OPEN ACCESS

Edited by:

Kun Zhang,

Southwest Petroleum University,

China

Reviewed by:

Du Weichao,

Xi'an Shiyou University, China

Peng Xu,

Yangtze University, China

Xiang Zhou,

Petroleum Systems Engineering,

Canada

*Correspondence:

Lu Liu

robin_liulu@msn.com

Specialty section:

This article was submitted to

Economic Geology,

a section of the journal

Frontiers in Earth Science

Received: 09 January 2022

Accepted: 24 January 2022

Published: 17 February 2022

Citation:

Li D, Jin J, Zhang D, Li F, Wang X and Liu $L$ (2022) pH-Responsive Drilling Fluid With High-Temperature and

High-Density Performance.

Front. Earth Sci. 10:851097.

doi: 10.3389/feart.2022.851097

\section{pH-Responsive Drilling Fluid With High-Temperature and High-Density Performance}

\author{
Daqi $L i^{1,2}$, Junbin Jin ${ }^{1,2}$, Dujie Zhang ${ }^{1,2}$, Fan $L i^{1,2}$, Xianguang Wang ${ }^{1,2}$ and $L u L i u^{3 *}$ \\ ${ }^{1}$ State Key Laboratory of Shale Oil and Gas Enrichment Mechanisms and Effective Development, Beijing, China, ${ }^{2}$ Sinopec \\ Research Institute of Petroleum Engineering, Beijing, China, ${ }^{3}$ State Key Laboratory of Oil and Gas Reservoir Geology and \\ Exploitation, Southwest Petroleum University, Chengdu, China
}

Conventional drilling fluids experience the problems of a low cleanup efficiency and oily drilled cutting disposal. To resolve these problems, a type of $\mathrm{pH}$-responsive drilling fluid with a temperature resistance of up to $150^{\circ} \mathrm{C}$ resistance a density of $1.5 \mathrm{~g} / \mathrm{cm}^{3}$ was prepared using mixed emulsifiers. Stable reversion from a water-in-oil (W/O) emulsion to an oil-in-water $(\mathrm{O} / \mathrm{W})$ and vice versa was realized. The results of light backscattering and sag stability suggested that the W/O and O/W emulsion-based drilling fluids showed excellent resistance to coalescence or sedimentation. There was no demulsification or barite sedimentation during emulsion reversion. W/O and O/W emulsions exhibited small droplet sizes and uniform distributions. The properties of the W/O and O/W emulsionbased drilling fluids were similar even after hot rolling at $150^{\circ} \mathrm{C}$ for $16 \mathrm{~h}$. The reversible drilling fluid showed excellent resistance to contamination by saline water and drilled cuttings. The residual W/O emulsion-based drilling fluid was cleaned with acids at a high efficiency. The oil content of the drill cuttings generated by the W/O emulsion-based drilling fluid was reduced using simple acids. The improved reversion stability with high temperature and density resistance makes it possible for applicable reversible drilling fluid in deep or ultra-deep wells required by different geological formation.

Keywords: high temperature, high density, pH-responsive, reversible drilling fluids, emulsion reversion

\section{INTRODUCTION}

Conventional oil-based drilling fluids typically have high emulsion stability and strong oil-wetting properties, which render contact drilling pipes, formation, and drill cuttings oil-wet (Nooripoor and Hashemi, 2020). In drilling procedures, strong oil-wetting properties are beneficial for improving shale formation stability and reducing downhole accidents. However, in follow-up cementing and completion procedures, strong oil-wetting properties make it difficult to efficiently remove the residual drilling fluid and filter cakes in a wellbore, which might result in poor cementing quality and production safety. In addition, it is expensive to dispose the oily drill cuttings that are produced by oil-based drilling fluids when they are circulated back to surfaces. Hence, maintaining the advantages of conventional drilling fluids while reducing their adverse effects is an emerging research topic.

Previous studies have proposed several methods to solve the follow-up problems associated with conventional oil-based drilling fluids, e.g., oil-based drilling fluid filter-cake removal (Bageri et al., 2019; Bageri et al., 2020), hole cleaning (Boyou et al., 2019; Guo et al., 2020), and waste oily drilled cutting processing (Sharma et al., 2020). However, these methods are expensive and complex, and 

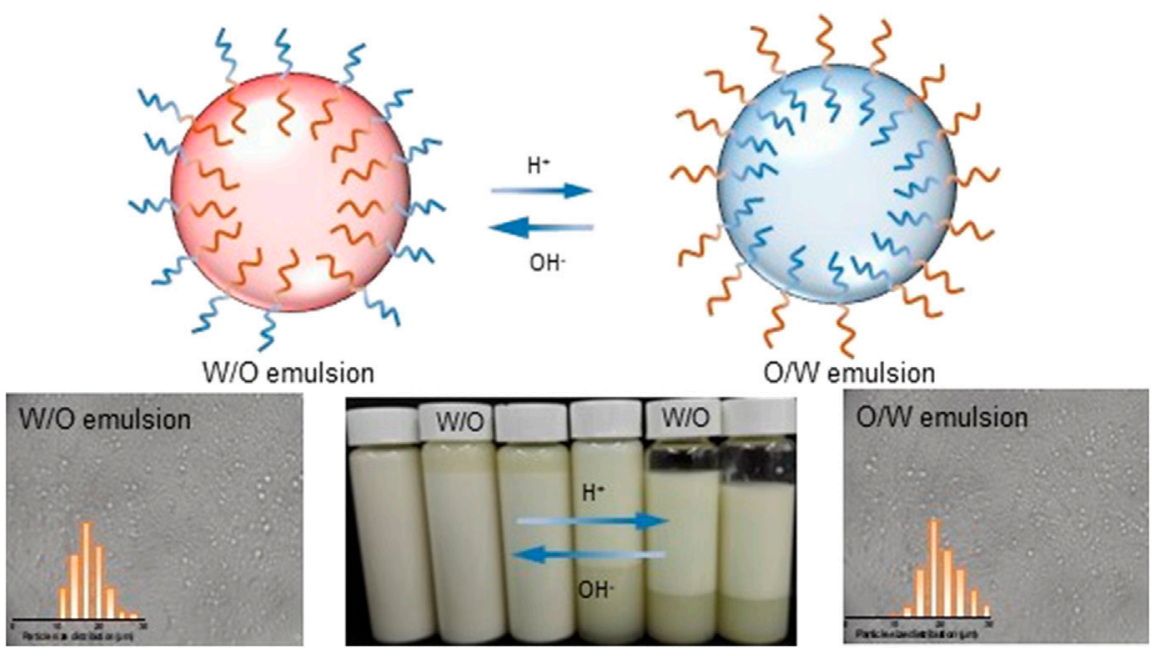

GRAPHICAL ABSTRACT |

they may cause secondary pollution. Controlling the wettability of oil-based drilling fluids is a promising new solution.

Patel (1999) proposed the first reversible emulsion drilling fluid in 1999. Reversible drilling fluids and conventional oil-based drilling fluids are different in terms of $\mathrm{pH}$-responsive emulsifiers (Patel, 1999; Patel et al., 1999; Patel and Ali, 2003). In drilling procedures, reversible drilling fluids are in the water-in-oil (W/O) emulsion phase, which provides advantages similar to those of conventional drilling fluids. In the follow-up cementing and completion stage, reversible drilling fluids are transformed into the oil-in-water $(\mathrm{O} / \mathrm{W})$ emulsion phase, which makes it easy to remove residual drilling fluids and filter cakes.

Reversible emulsions can be stimulated by magnetism (Brugger and Richtering, 2007; Chen et al., 2014), electricity (Quesada et al., 2013), temperature (Binks et al., 2005; Destribats et al., 2012), electrolytes (Cui et al., 2008; Cui et al., 2012; Ren et al., 2017; Xu et al., 2018), pH (Read et al., 2004; Fujii et al., 2005; Binks and Rodrigues, 2007; Haase et al., 2010; Dyab, 2012; Ghosn et al., 2017), and the $\mathrm{CO}_{2} / \mathrm{N}_{2}$ (Zhang et al., 2016; Shi et al., 2018; Guo and Zhang, 2019) or volume ratio (Popov et al., 2013). Among these, $\mathrm{pH}$ responsive emulsions are one of the simplest and most readily implementable systems (Tang et al., 2015). Amine surfactants form responsive emulsions by transitioning from a surface-active substance (cationic ammonium) to a non-surface-active substance (neutral tertiary amine) upon exposure to $\mathrm{CO}_{2} / \mathrm{N}_{2}$ (Zhang et al., 2016), (Guo and Zhang, 2019), (Tang et al., 2015), (Shi et al., 2019). This transition depends on the $\mathrm{pH}$ change in the aqueous solution $(\mathrm{pH}=5-10)$. However, current reversible drilling fluids stabilized by amine emulsifiers in oil fields have a typical temperature resistance of $120^{\circ} \mathrm{C}$, and their density is lower than $1.2 \mathrm{~g} / \mathrm{cm}$ (Dick et al., 2003; Ali et al., 2004; Bageri et al., 2019). These properties cannot meet the requirements of deep downhole environments. Furthermore, W/O drilling fluids have been extensively investigated, whereas $\mathrm{O} / \mathrm{W}$ drilling fluids are difficult to use owing to their instability.

Even though numerous responsive emulsifiers have been developed, it is difficult to control the emulsion reversion stability in high-temperature and high-pressure conditions. The breakdown of drilling fluids in downhole environments increases the risk of drilling accidents and decreases drilling safety. Therefore, the emulsion reversion stability and effectiveness can be used as a basis to develop a reversible drilling fluid that is, suitable for downhole environments. High-temperature resistance and high-density capacity require the reformulation of the reversible drilling fluid system.

In this study, we formulated a reversible drilling fluid with high temperature resistance and high density for deep or ultra-deep wells. Stable reversion from a water-in-oil (W/O) emulsion to an oil-in-water $(\mathrm{O} / \mathrm{W})$ and vice versa was realized. This work can provide guidance for the potential applications of reversible drilling fluids in wellbores.

\section{MATERIALS AND METHODS}

Experiments were performed using diesel oil purchased from a Shell gas station in Chengdu, Sichuan, China. The water used in the experiments was deionized using a Milli-Q reagent water system. A long-chain polyamine primary surfactant (hereinafter referred to as RPEM) was prepared according to a previously reported procedure (Zhang et al., 2013; Zhang et al., 2015). Sodium hydroxide (AR) and hydrochloric acid (35\%, AR), which were obtained from Chengdu Kelong Reagent Plant, Chengdu, Sichuan, China, were used to adjust the $\mathrm{pH}$ of the solution. Organoclay, a filtration loss reducer, and a weight material (barite) were obtained from Chengdu Xiyouhuawei Science \& Technology Co., Ltd. Surfactant flushing fluid was obtained from an oil field.

\section{Preparation and Characterization of Emulsions \\ Emulsion Preparation}

Equal volumes $(150 \mathrm{ml})$ of the diesel oil phase containing RPEM and the aqueous phase $(150 \mathrm{ml})$ were emulsified using a highspeed stirrer at $10,000 \mathrm{rpm}$ for $30 \mathrm{~min}-1 \mathrm{~h}$ at room temperature 
$\left(25 \pm 5^{\circ} \mathrm{C}\right)$. It should be noted that the surfactant concentrations mentioned in this paper refer to the content in the initial oil phase and are not based on the total volume. Emulsion drop size distributions were determined using a particle size distribution analyzer (LA-950V2, Horiba Scientific, China). The optical images of the emulsions were obtained via an inverted fluorescence digital microscope (AMG EVOSFL, Advanced Microscopy Group, USA). $\mathrm{pH}$ values for emulsions were detected by using PHS-3C.

\section{Emulsion Reversion}

The $\mathrm{pH}$ was adjusted by adding $1 \mathrm{M} \mathrm{NaOH}$ and/or $1 \mathrm{M} \mathrm{HCl}$ in a dropwise manner. As the addition of $\mathrm{pH}$ solution is minimal, its impact on the water-oil ratio is negligible. Immediately after emulsification, the emulsion type was determined by adding an emulsion drop to either pure oil or pure water. The emulsion was the $\mathrm{O} / \mathrm{W}$ type if the drop dispersed in pure water and remained a drop in pure oil, and vice versa for the W/O type.

\section{Emulsion Stability}

The emulsions were transferred into stoppered and graduated glass vessels with inner diameters of $1.8 \mathrm{~cm}$ and lengths of $7 \mathrm{~cm}$ while maintaining the temperature at $25^{\circ} \mathrm{C}$. For W/O emulsions, the downward movement of the oil-emulsion boundary was used as a measure of sedimentation and the change in the water-emulsion interface position was used as an indicator of coalescence. The extent of creaming in $\mathrm{O} / \mathrm{W}$ emulsions was obtained by measuring the height of water resolved from the emulsions. The extent of sedimentation in $\mathrm{O} / \mathrm{W}$ emulsions was obtained by measuring the height of oil resolved from the emulsions.

\section{Conductivity}

The conductivity of the emulsions was measured using a digital conductivity meter immediately after preparation. The emulsions with a high conductivity were classified as $\mathrm{O} / \mathrm{W}$ emulsions or $\mathrm{W} / \mathrm{O} / \mathrm{W}$ emulsions and those with a low (immeasurable) conductivity $\left(<1 \mu \mathrm{S} \mathrm{cm}^{-1}\right)$ were classified as $\mathrm{W} / \mathrm{O}$ emulsions or $\mathrm{O} / \mathrm{W} / \mathrm{O}$ emulsions.

\section{Demulsification Voltage (ES)}

The ES values of the emulsions were determined using an electrical stability tester (DWY-2, Qingdao Tongchun Oil Instrument Co., Ltd., China) with an electrode distance of $1.55 \pm 0.04 \mathrm{~mm}$. The ES value is mainly used to measure the relative stability of $\mathrm{W} / \mathrm{O}$ emulsions. A high electrical stability indicates high emulsion stability. The voltage required to break $\mathrm{O} / \mathrm{W}$ emulsions is typically quite low $(<10 \mathrm{~V})$.

\section{Characterization of Reversible Drilling Fluid}

The emulsions were thermally aged in a rotary oven at different temperatures for $16 \mathrm{~h}$ to model actual drilling operation conditions, in accordance with the American Petroleum Institute (API) SPEC 13A and RP 13B-2 standards for drilling fluids.

\section{HTHP Filtration Loss}

The HTHP filtration volume $\left(\mathrm{FL}_{\mathrm{HTHP}}\right)$ was collected using a high-temperature and high-pressure filtration apparatus (GGS42,
Qingdao Tongchun Machinery Petroleum instrument, China) by applying a pressure of $4.2 \pm 0.03 \mathrm{MPa}$ at a given temperature.

\section{Rheology Test}

The rheological parameters, i.e., apparent viscosity $(A V)$, plastic viscosity $(P V)$, and yield point $(Y P)$, were obtained using a sixspeed rotational viscometer (ZNN-D6, Qingdao Tongchun Petroleum Instrument Co., China) at 600 and $300 \mathrm{rpm}$. They were calculated as follows:

$$
\begin{gathered}
A V=\frac{1}{2} \theta_{600}(\mathrm{mPa} \cdot \mathrm{s}) \\
P V=\theta_{600}-\theta_{300}(\mathrm{mPa} \cdot \mathrm{s}) \\
Y P=\frac{1}{2}\left(\theta_{600}-P V\right)(\mathrm{Pa})
\end{gathered}
$$

$\theta_{600}$ and $\theta_{300}$ denote the dial readings on the viscometer at 600 and $300 \mathrm{rpm}$, respectively. To reach steady conditions, the fluids were stirred for $10 \mathrm{~min}$ prior to rheological measurements. $G_{10 s} / G_{10 m i n}$ were the gel strength obtained at $10 \mathrm{~s}$ and $10 \mathrm{~min}$ for dial readings at $3 \mathrm{rpm}$. The experimental error for viscosity was always below $\pm 5 \%$.

\section{Filter-Cake Cleanup}

Filter cakes were built by immersing the rotational viscometer in the drilling fluids for $1 \mathrm{~h}$. Then, the viscometer cylinders were soaked in washing fluids for $10 \mathrm{~min}$ to remove the filter cakes on their surfaces. The cleanup efficiency of the filter cakes was calculated by recording the differences in the weights of the cylinders before and after immersion.

\section{Drilled Cuttings}

Oily drill cuttings at 10-40 mesh, obtained from shale formation, were prepared by hot rolling the drilling fluids at $150^{\circ} \mathrm{C}$ for $16 \mathrm{~h}$ and sieving at room temperature. The oil content of the drill cuttings was measured using a Soxhlet extractor and refluxed for $12 \mathrm{~h}$ using petroleum ether.

\section{Sag Test}

The densities of the top and bottom sections of the drilling fluids were measured after static standing for $24 \mathrm{~h}$. The sag factor (SF) was calculated as follows: $\mathrm{SF}=\frac{\rho_{\text {bottom }}}{\rho_{\text {top }}+\rho_{\text {bottom }}}$.

\section{Emulsion Stability}

Emulsion destabilization results from coalescence or flocculation was measured on a Multiple light scattering analyzer TURBISCAN MA 2000 at room temperature $\left(25 \pm 5^{\circ} \mathrm{C}\right)$.

\section{RESULTS AND DISCUSSION}

\section{Emulsification Efficiency}

The $\mathrm{pH}$-dependent behavior of the emulsion stabilized by only RPEM (2 wt\%) was investigated in detail. Figure 1 shows the variation in the ES value, conductivity, $\mathrm{pH}$, and continuous phase resolution of the $\mathrm{pH}$-responsive emulsion on the addition of the acid.

A stable W/O emulsion is generated by RPEM. As the acid concentration increases, the ES value significantly decreases from 

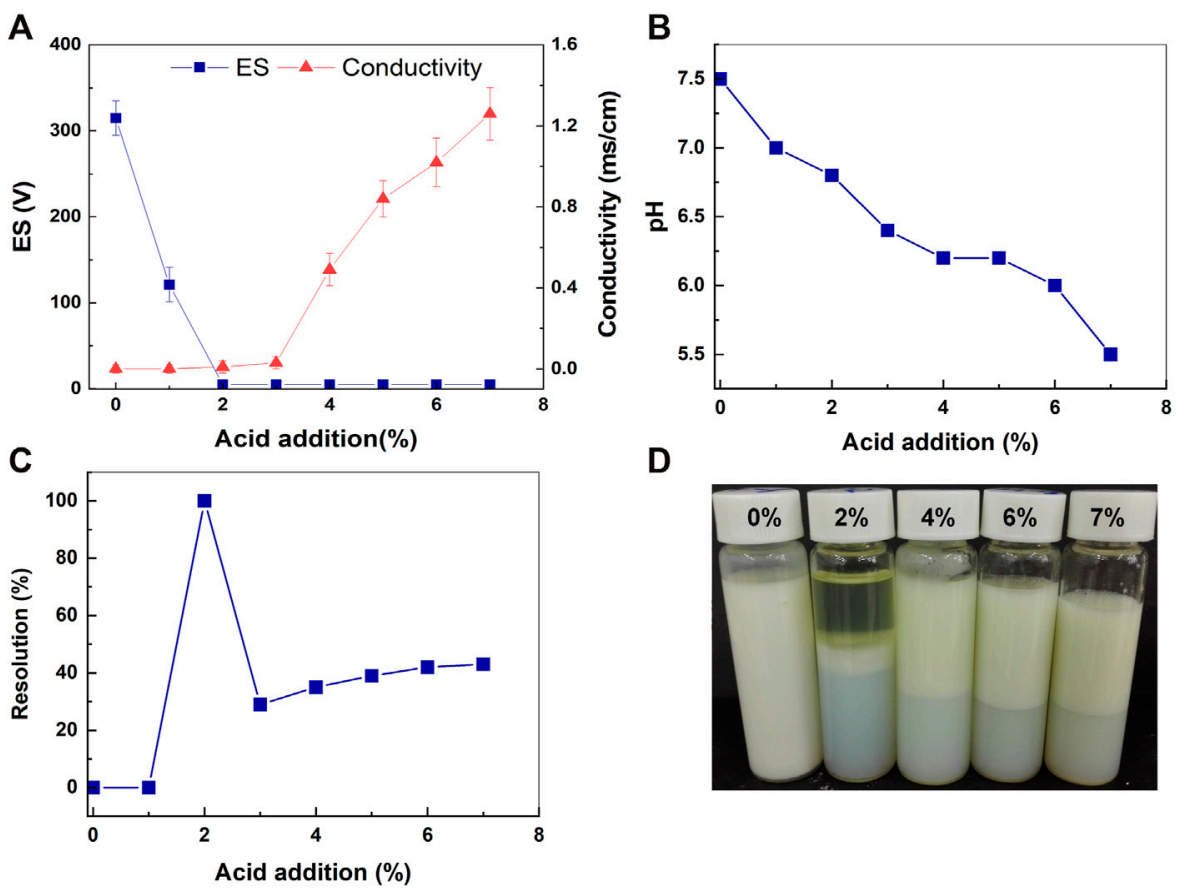

FIGURE 1 | (A) ES values (blue circles) and conductivities (red triangles) of emulsion stabilized by 2 wt $\%$ RPEM at room temperature (25 $\left.\pm 5^{\circ} \mathrm{C}\right)$. (B) pH values of emulsion during reversion. (C) Continuous phase resolution of emulsion. (D) Images obtained $2 \mathrm{~h}$ after the emulsions were prepared.

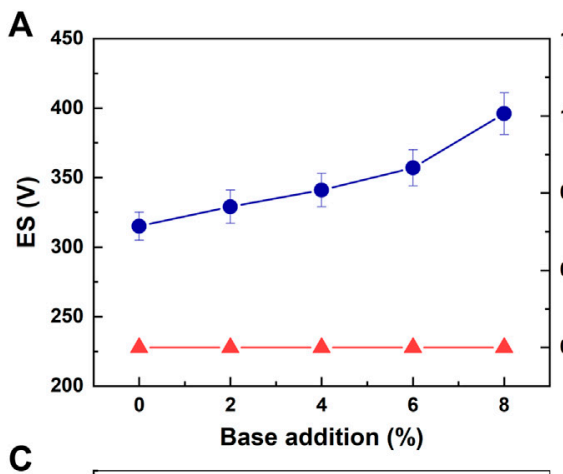

C

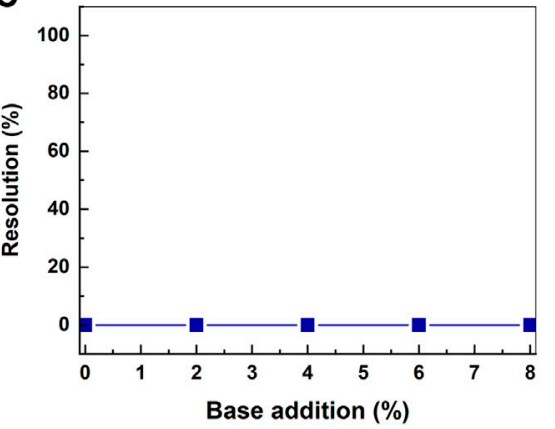

B
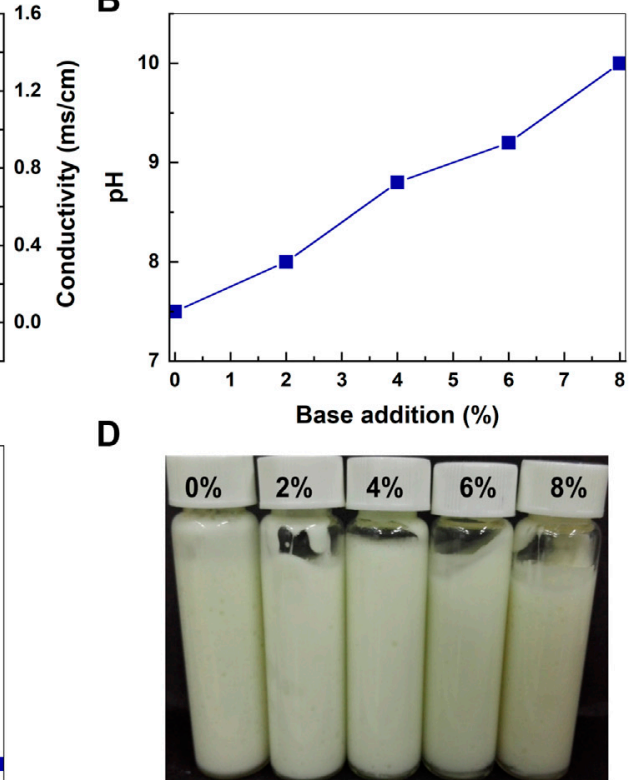

W/O

FIGURE 2 | (A) ES values (blue circles) and conductivities (red triangles) of emulsion stabilized by 2 wt $\%$ RPEM at room temperature (25 $\pm 5^{\circ} \mathrm{C}$ ). (B) pH values of emulsion during reversion. (C) Continuous phase resolution of emulsion. (D) Images obtained $2 \mathrm{~h}$ after the emulsions were prepared. 

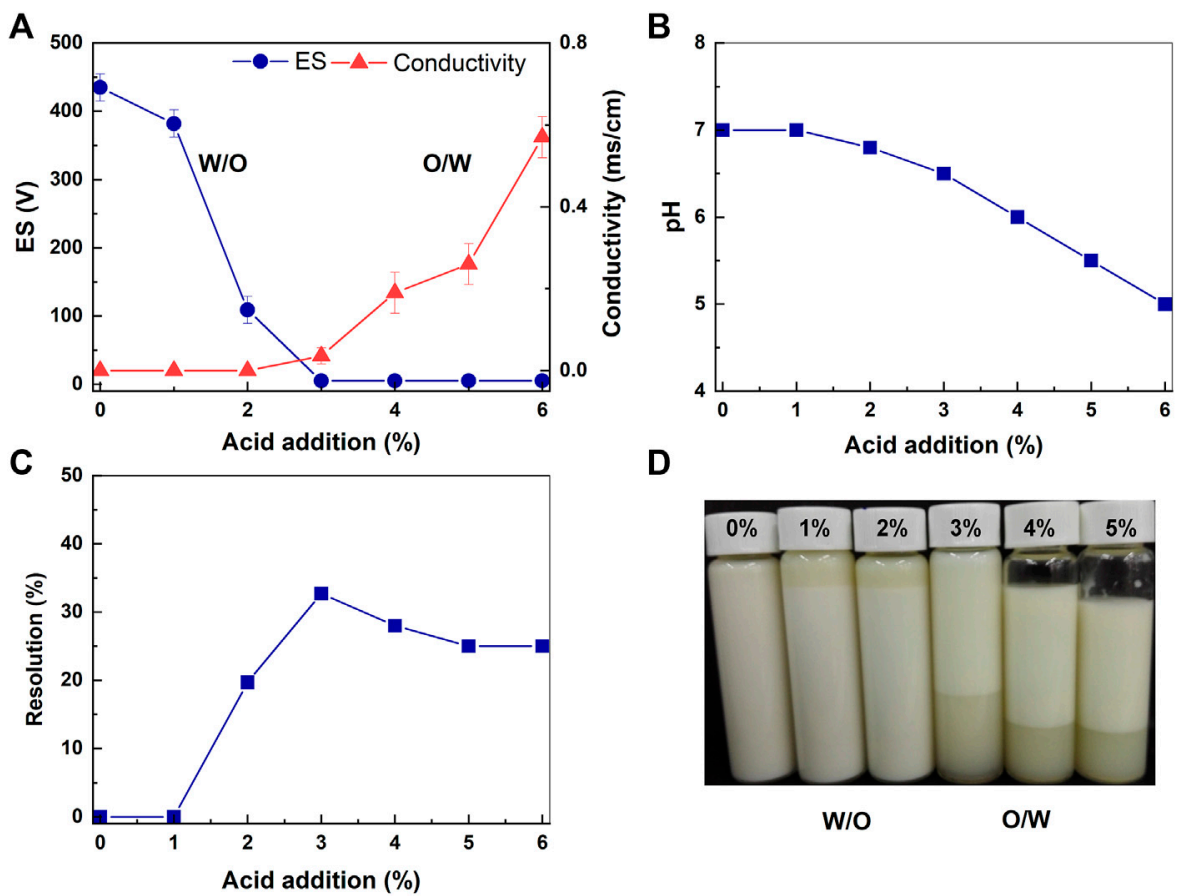

FIGURE 3 | (A) ES values (blue circles) and conductivities (red triangles) of emulsion stabilized by two emulsifiers in a ratio of $2: 1$ at room temperature (25 $\pm 5^{\circ} \mathrm{C}$ ). (B) $\mathrm{pH}$ values of emulsion during reversion. (C) Continuous phase resolution of emulsion. (D) Images obtained $2 \mathrm{~h}$ after the emulsions were prepared.

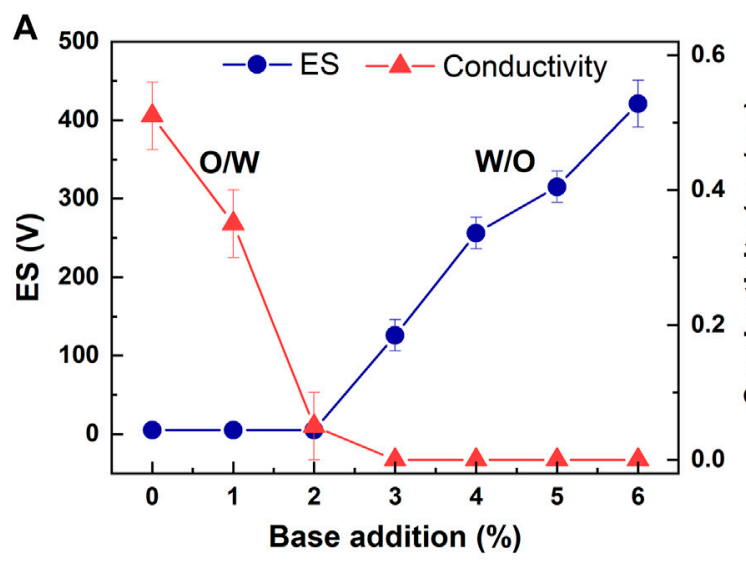

C

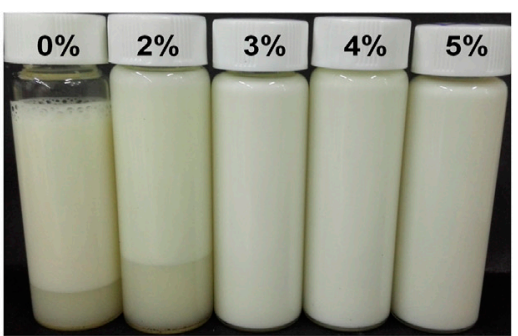

O/W
D

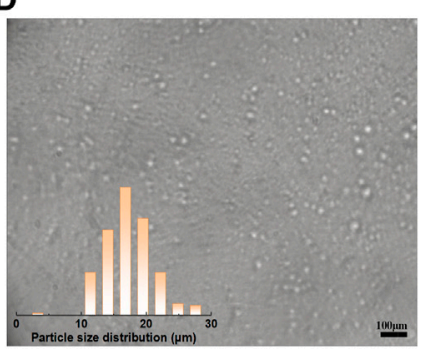

W/O

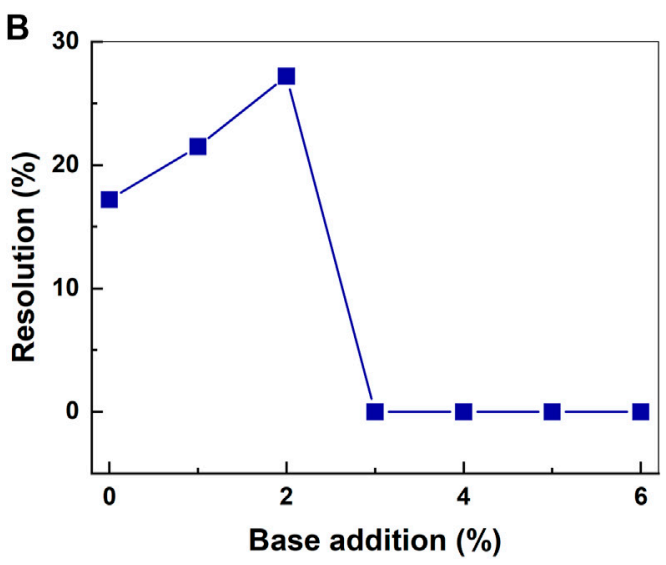

E

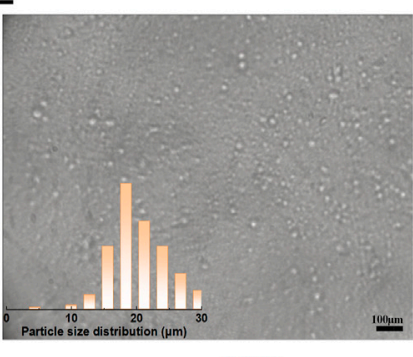

O/W

FIGURE 4 | (A) ES values (blue circles) and conductivities (red triangles) of emulsion stabilized by two emulsifiers in a ratio of $2: 1$ at room temperature (25 $\pm 5^{\circ} \mathrm{C}$ ). (B) Continuous phase resolution of emulsion during reversion. (C) Images obtained $2 \mathrm{~h}$ after the emulsions were prepared. (D) Droplet size distributions for W/O emulsion and (E) ON emulsion. The scale bar is $100 \mu \mathrm{m}$. 
TABLE 1 | Performance of reversible drilling fluid at different hot-rolling temperatures.

\begin{tabular}{|c|c|c|c|c|c|c|c|}
\hline \multirow[t]{2}{*}{ Hot-rolling temperature $/{ }^{\circ} \mathrm{C}$} & \multirow[t]{2}{*}{ Emulsion type } & \multirow{2}{*}{$\frac{E S}{N}$} & \multirow{2}{*}{$\frac{\mathrm{AV}}{/ \mathrm{mPa} \cdot \mathrm{s}}$} & \multirow{2}{*}{$\frac{\mathrm{PV}}{/ \mathrm{mPa} \cdot \mathrm{s}}$} & \multirow[t]{2}{*}{ YP/Pa } & \multirow[t]{2}{*}{$\mathbf{G}_{10 s} / \mathbf{G}_{10 \min }$} & \multirow{2}{*}{$\frac{\mathrm{FL}_{\mathrm{HTHP}}}{\mathrm{/mL}}$} \\
\hline & & & & & & & \\
\hline \multirow[t]{2}{*}{100} & W/O & 467 & 56.5 & 45 & 11.5 & $3.0 / 3.5$ & 3.8 \\
\hline & O/W & 4 & 58.5 & 47 & 11.5 & $3.5 / 4.0$ & 4.2 \\
\hline \multirow[t]{2}{*}{120} & W/O & 444 & 52.0 & 40 & 12 & $2.5 / 3.5$ & 3.6 \\
\hline & $\mathrm{O} / \mathrm{W}$ & 3 & 53.5 & 41 & 12.5 & $3.0 / 3.5$ & 6.2 \\
\hline \multirow[t]{2}{*}{150} & W/O & 422 & 51.5 & 40 & 11.5 & $3.0 / 4.0$ & 4.8 \\
\hline & $\mathrm{O} / \mathrm{W}$ & 6 & 50.5 & 39 & 11.5 & $3.5 / 4.5$ & 8.2 \\
\hline \multirow[t]{2}{*}{180} & W/O & 354 & 30.5 & 22 & 8.5 & $1.0 / 1.5$ & 16.8 \\
\hline & $\mathrm{O} / \mathrm{W}$ & 6 & 38.5 & 30 & 8.5 & $1.5 / 1.5$ & 18.4 \\
\hline
\end{tabular}

TABLE 2 | Variation in density of reversible drilling fluid.

\section{Density}

Density

Top section $\left(\mathrm{g} / \mathrm{cm}^{3}\right)$

Bottom section $\left(\mathrm{g} / \mathrm{cm}^{3}\right)$

Density variation $\left(\mathrm{g} / \mathrm{cm}^{3}\right)$

SF
W/O emulsion-based drilling fluid

1.48

1.53

0.05

0.508
O/W emulsion-based drilling fluid

1.47

1.51

0.04

0.507

\begin{tabular}{|c|c|c|c|c|c|c|c|}
\hline Salinity & Emulsion type & ES/V & AV/mPa.s & $\mathrm{PV} / \mathrm{mPa} \cdot \mathrm{s}$ & YP/Pa & $\mathrm{G}_{10 \mathrm{~s}} / \mathrm{G}_{10 \mathrm{~min}}$ & $\mathrm{FL}_{\mathrm{HTHP}} / \mathrm{mL}$ \\
\hline \multirow[t]{2}{*}{0} & W/O & 422 & 51.5 & 40 & 11.5 & $3.0 / 4.0$ & 4.8 \\
\hline & $\mathrm{ON}$ & 6 & 50.5 & 39 & 11.5 & $3.5 / 4.5$ & 8.2 \\
\hline \multirow[t]{2}{*}{$5 \% \mathrm{CaSO}_{4}$} & W/O & 419 & 53.5 & 41 & 12.5 & $3.0 / 3.5$ & 5.2 \\
\hline & $\mathrm{OM}$ & 6 & 49.5 & 39 & 10.5 & $3.0 / 4.0$ & 6.4 \\
\hline \multirow[t]{2}{*}{$5 \% \mathrm{NaCl}$} & W/O & 427 & 59.0 & 47 & 12.0 & $2.5 / 3.0$ & 6.2 \\
\hline & OM & 6 & 55.5 & 43 & 12.5 & $2.0 / 2.5$ & 7.2 \\
\hline \multirow[t]{2}{*}{$10 \% \mathrm{NaCl}$} & W/O & 401 & 63.5 & 50 & 13.5 & $3.0 / 4.0$ & 7.4 \\
\hline & $\mathrm{O} / \mathrm{W}$ & 6 & 59.5 & 48 & 11.5 & $2.5 / 3.5$ & 8.4 \\
\hline
\end{tabular}

315 to $5 \mathrm{~V}$ and conductivity increases from 0 to $1.26 \mathrm{~ms} / \mathrm{cm}$. At an acid concentration of $4 \%$, the emulsion is reversed to an $\mathrm{O} / \mathrm{W}$ emulsion with a high conductivity and low ES value. However, the emulsion reversion experiences become unstable at an acid concentration of $2 \%$ when the $\mathrm{pH}$ is lower than 7 . The oil-phase and water-phase resolutions increase simultaneously, suggesting demulsification. The hydrophilicity of RPEM increases because amine protonation occurs as the $\mathrm{pH}$ value decreases. This leads to the formation of an $\mathrm{O} / \mathrm{W}$ emulsion. However, sedimentation is likely in the reversed $\mathrm{O} / \mathrm{W}$ emulsion with a high water-phase resolution, which may be due to insufficient hydrophilic groups.

Figure 2 shows the variation in the ES value, conductivity, $\mathrm{pH}$, and continuous phase resolution of the emulsion on the addition of the base. As the base concentration increases, the oil-phase resolution of the W/O emulsion stabilized by only RPEM is close to $0 \%$. In addition, the $\mathrm{ES}$ value increases with the $\mathrm{pH}$, indicating that the W/O emulsion stability increases under basic conditions.
We incorporated a secondary emulsifier (1\% RZ-1) into the emulsion system to improve the emulsion reversion stability. Figure 3 shows the variation in the ES value, conductivity, $\mathrm{pH}$, and continuous phase resolution of the $\mathrm{pH}$-responsive emulsion stabilized by the emulsifier on the addition of an acid.

The initial ES value of the W/O emulsion stabilized by $2 \%$ RPEM and $1 \%$ RZ-1 is $435 \mathrm{~V}$, which meets the API standard (ES > $400 \mathrm{~V})$. As the acid concentration increases to $3 \%$, the ES value decreases to $5 \mathrm{~V}$. In addition, the conductivity increases to $0.57 \mathrm{~ms} / \mathrm{cm}$, indicating the reversion to an $\mathrm{O} / \mathrm{W}$ emulsion. Even though the water-phase resolution of $\mathrm{O} / \mathrm{W}$ emulsions is $25 \%$, demulsification does not occur at any acid concentration. Therefore, by decreasing $\mathrm{pH}$ value from 7 to 5 , the protonation of amine groups renders the increasing hydrophilicity of emulsifiers, leading to stable reversion from a $\mathrm{W} / \mathrm{O}$ emulsion to an $\mathrm{O} / \mathrm{W}$ emulsion.

Figure 4 shows the variation in the ES value, conductivity, and continuous phase resolution of the $\mathrm{pH}$-responsive emulsion stabilized 

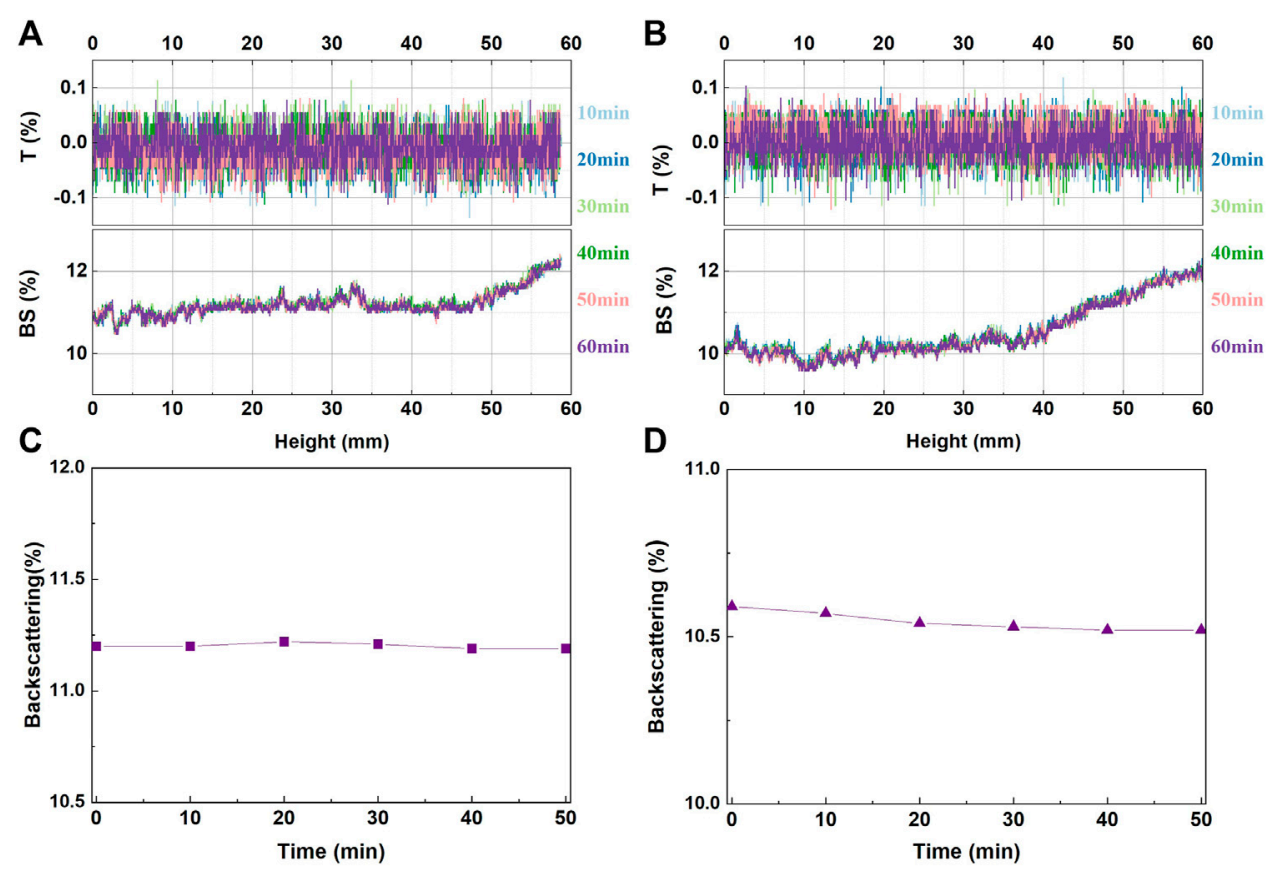

FIGURE 5 | Transmission (top) and backscattering (bottom) profiles of (A) W/O and (B) O/W emulsion-based drilling fluids. (C) Stability kinetics over the entire sample height for the W/O and (D) O/W emulsion-based drilling fluids.

TABLE 4 | Properties of reversible drilling fluid contaminated by drill cuttings.

\begin{tabular}{|c|c|c|c|c|c|c|c|}
\hline Drill cuttings/\% & Emulsion type & ES/V & AV/mPa.s & $\mathrm{PV} / \mathrm{mPa} \cdot \mathrm{s}$ & $\mathrm{YP} / \mathrm{Pa}$ & $\mathbf{G}_{10 s} / G_{10 \min }$ & $\mathrm{FL}_{\mathrm{HTHP}} / \mathrm{mL}$ \\
\hline \multirow[t]{2}{*}{0} & W/O & 422 & 51.5 & 40 & 11.5 & $3.0 / 4.0$ & 4.8 \\
\hline & $\mathrm{O} / \mathrm{W}$ & 6 & 50.5 & 39 & 11.5 & $3.5 / 4.5$ & 8.2 \\
\hline \multirow[t]{2}{*}{5} & W/O & 436 & 56.5 & 43 & 13.5 & $3.0 / 3.5$ & 5.4 \\
\hline & $\mathrm{O} / \mathrm{W}$ & 6 & 58.5 & 46 & 12.5 & $3.5 / 4.0$ & 6.2 \\
\hline \multirow[t]{2}{*}{10} & W/O & 461 & 60.5 & 46 & 14.5 & $3.5 / 4.5$ & 7.2 \\
\hline & $\mathrm{O} / \mathrm{W}$ & 6 & 63.5 & 50 & 13.5 & $4.0 / 5.5$ & 8.2 \\
\hline
\end{tabular}

by the emulsifier on the addition of the base. The conductivity decreases as the base concentration increases. At a base concentration of 3\%, the conductivity decreases to $0 \mathrm{~ms} / \mathrm{cm}$ and the ES value increases to $100 \mathrm{~V}$, suggesting the reversion from an $\mathrm{O} / \mathrm{W}$ emulsion to a $\mathrm{W} / \mathrm{O}$ emulsion. As the base concentration increases to $6 \%$, the ES value of the $\mathrm{W} / \mathrm{O}$ emulsion recovers back to $421 \mathrm{~V}$ and oil resolves minimally, indicating a stable W/O emulsion. Demulsification is not observed during the reversion from an $\mathrm{O} / \mathrm{W}$ emulsion to a $\mathrm{W} / \mathrm{O}$ emulsion.

Figures 4D,E show that the mean emulsion droplet sizes of the $\mathrm{W} / \mathrm{O}$ and $\mathrm{O} / \mathrm{W}$ emulsions before and after emulsion reversion are less than $21 \mu \mathrm{m}$ and uniformly distributed. It can be concluded that stable reversion from an $\mathrm{O} / \mathrm{W}$ emulsion to a $\mathrm{W} / \mathrm{O}$ emulsion and vice versa can be achieved by changing the $\mathrm{pH}$ values.

\section{Drilling Fluid Performance High-Temperature Resistance}

We examined the performance of $\mathrm{W} / \mathrm{O}$ and $\mathrm{O} / \mathrm{W}$ emulsion-based drilling fluids. Drilling fluid was prepared using the optimal formula:
TABLE 5 | Cleanup efficiency of reversible drilling fluid at different $\mathrm{pH}$ values.

pH value

Cleanup efficiency \%

Water contact angle ( ${ }^{\circ}$ )

$\begin{array}{llc}7 & 47.2 & 116.5 \\ 6 & 63.5 & 92.7 \\ 5 & 86.3 & 56.4 \\ 4 & 90.7 & 34.8 \\ 3 & 95.1 & 23.6 \\ \text { Surfactant flushing fluid } & 89.4 & 36.1\end{array}$

2 wt $\%$ PREM+1 wt\% RZ-1+1 wt $\%$ organoclay+3 wt $\%$ filtrate loss reducer. The drilling fluid density was adjusted to $1.5 \mathrm{~g} / \mathrm{cm}^{3}$ using barite. The drilling fluid was hot rolled for $16 \mathrm{~h}$ at various temperatures and then cooled to $65^{\circ} \mathrm{C}$ for performance testing according to the API standard. The results are presented in Table $\mathbf{1 .}$

Based on the API standard for oil-based drilling fluids, on-site practice requires an ES value above $400 \mathrm{~V}$ to ensure emulsification 


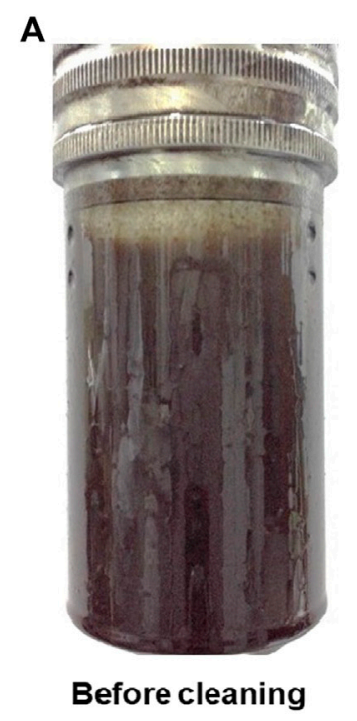

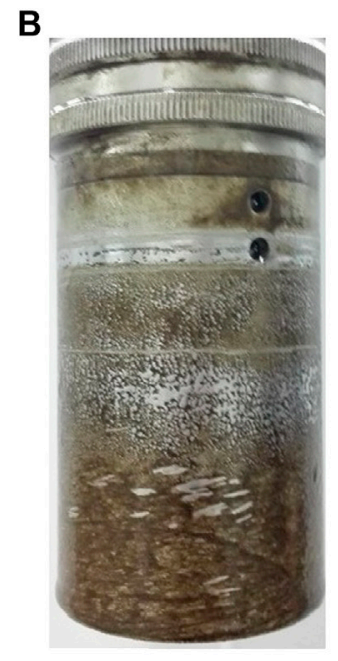

Acid cleaning at $\mathrm{pH} 5$

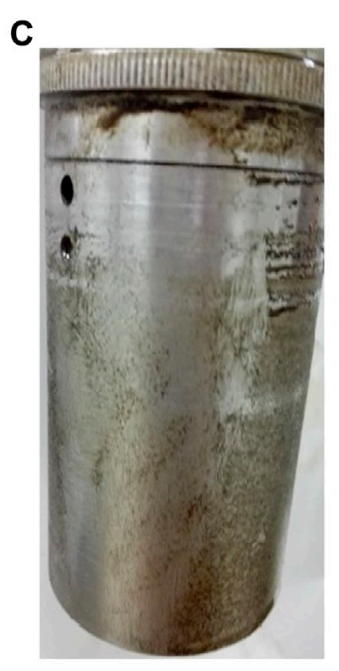

Acid cleaning at $\mathrm{pH} 3$

FIGURE 6 | (A) Viscometer cylinder covered by reversible drilling fluid before washing. (B) Cleanup efficiency for reversible drilling fluid washed by acid at pH = 5 and (C) $\mathrm{pH}=3$.

stability in a wellbore. Table 1 shows that the ES value of the W/O emulsion-based drilling fluid is over $400 \mathrm{~V}$ even after hot rolling at temperatures of $100-150^{\circ} \mathrm{C}$, indicating excellent emulsion stability even at a low oil-to-water ratio. Normally, low oil-to-water ratio usually makes it difficult to maintain high emulsion stability and suitable rheology (Oltedal et al., 2015). The rheological properties of the $\mathrm{O} / \mathrm{W}$ emulsion-based drilling fluid after reversion are similar to those of the W/O emulsion-based drilling fluid, and there is no severe demulsification or barite sag during emulsion reversion. This suggests that the $\mathrm{W} / \mathrm{O}$ and $\mathrm{O} / \mathrm{W}$ emulsion-based drilling fluids exhibit excellent rheology and low filtration loss (less than $10 \mathrm{ml}$ ), which meets drilling engineering requirements.

\section{Sag Stability}

In high-density drilling fluids, weighting materials tend to settle because of gravity. This might result in a loss of circulation, drilling-pipe sticking, well-control difficulty, and cementing problems (Elkatatny, 2018). In reversible drilling fluids, weighting materials must be transferred between the oil and water phases during emulsion reversion, which might increase density variation. Therefore, the sag stability of reversible drilling fluids was examined at a density of $1.5 \mathrm{~g} / \mathrm{cm}^{3}$. The drilling fluid density variations at the top and bottom sections were measured for $\mathrm{W} / \mathrm{O}$ and $\mathrm{O} / \mathrm{W}$ emulsion-based drilling fluids, and the results are shown in Table 2.

The SFs for both types of drilling fluids are less than 0.52 , and the density variation is less than $0.05 \mathrm{~g} / \mathrm{cm}^{3}$ (Table 2), confirming the prevention of barite sagging (Elkatatny, 2019). Weighting materials are well suspended in the system, and the density of the reversible drilling fluids is uniformly distributed, indicating excellent sedimentation ability.

A multiple light scattering analyzer is a nonintrusive instrument used to investigate destabilization mechanisms without dilution or stress (Mengual et al., 1999). The scattering and transmission rates for the $\mathrm{W} / \mathrm{O}$ and $\mathrm{O} / \mathrm{W}$ emulsion-based drilling fluids after hot rolling at $150^{\circ} \mathrm{C}$ for $16 \mathrm{~h}$ were measured, and the results are shown in Figure 5.
TABLE 6 | Reduction in oil content of drill cuttings generated by reversible drilling fluid.

\begin{tabular}{lc} 
pH value & $\begin{array}{r}\text { Oil content of } \\
\text { drill cuttings/\% }\end{array}$ \\
\hline Blank sample & 35.5 \\
7 & 29.3 \\
6 & 19.5 \\
5 & 16.2 \\
4 & 3.2 \\
3 & 1.3
\end{tabular}

The backscattering (BS) rates for the $\mathrm{W} / \mathrm{O}$ and $\mathrm{O} / \mathrm{W}$ emulsion drilling fluids overlap for $1 \mathrm{~h}$. The mean values of the backscattering rate for the test sample height are almost the same for $1 \mathrm{~h}$, suggesting that the emulsions are uniformly distributed. There is no creaming or sedimentation. These results show that the reversible drilling fluids with a density of $1.5 \mathrm{~g} / \mathrm{cm}^{3}$ achieve stable emulsion reversion even after hot rolling at $150^{\circ} \mathrm{C}$ for $16 \mathrm{~h}$.

\section{Contamination Test}

Contamination, such as by saline water or drill cuttings, typically occurs when drilling into deep formations. Therefore, it is necessary to evaluate the performance of the reversible drilling fluids contaminated by various salts or drill cuttings. Table 3 shows the properties of the drilling fluid contaminated by saline water.

The rheology of the contaminated reversible drilling fluid increases owing to the increased saline water ratio. More water droplets in the dispersed phase cause flow friction. On the other hand, the rheological properties for $\mathrm{O} / \mathrm{W}$ emulsion are smaller than $\mathrm{W} / \mathrm{O}$ emulsion when contaminated by saline water, as more continuous phase fraction for $\mathrm{O} / \mathrm{W}$ emulsion. The ES values for the W/O emulsions remain above $400 \mathrm{~V}$, indicating excellent salinity tolerance. The filtration loss for both W/O emulsion and $\mathrm{O} / \mathrm{W}$ emulsion are less than $10 \mathrm{ml}$, which 

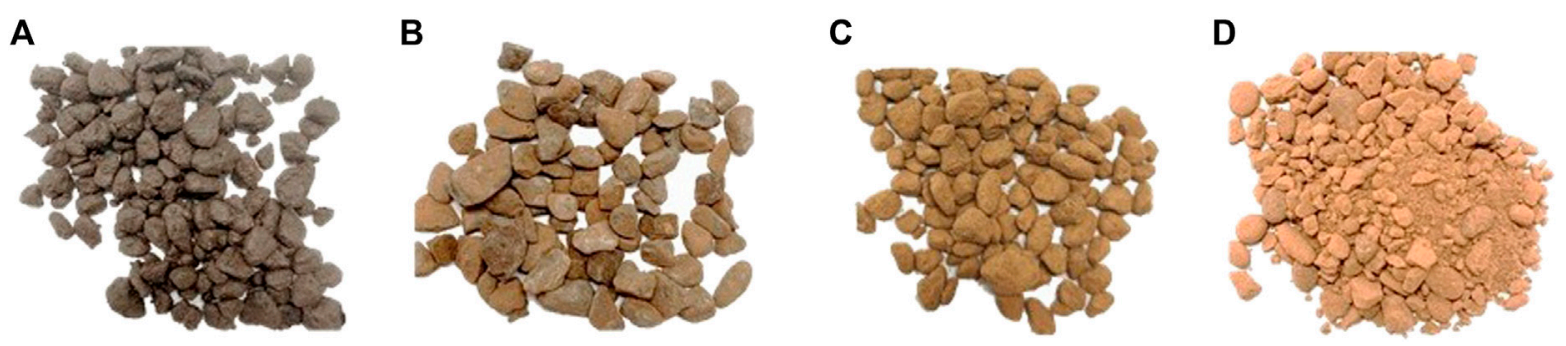

FIGURE 7 | (A) Raw drill cuttings generated by reversible drilling fluid after hot rolling. (B) Drill cuttings washed by acid at $\mathrm{pH}=6$, (C) $\mathrm{pH}=5$, and (D) $\mathrm{pH}=3$ (D).

meets the API standard. These results show that the properties of the reversible drilling fluid can be adjusted to maintain stability in wellbores even exposed to gypsum formation.

Table 4 shows the properties of the reversible drilling fluid contaminated with drill cuttings. Both $\mathrm{W} / \mathrm{O}$ and $\mathrm{O} / \mathrm{W}$ emulsion drilling fluid show excellent resistance to drill cuttings contamination. The AV, PV, and YP of the reversible drilling fluid increase with the amount of drill cuttings owing to the overload solid content that resists flow mobility. However, the rheological properties and filtration loss properties are within an acceptable range when the drilling fluid is contaminated with $10 \%$ cuttings.

\section{Cleanup Efficiency}

In the case of conventional oil-based drilling fluids, large amounts of surfactants and complicated cleaning procedures are required to remove the residual drilling fluid and filter cakes from wellbores and drilling pipes for high-quality cement bonding. Reversible drilling fluids are expected to improve the cleanup efficiency. To verify this, the cleanup efficiency of the as-prepared reversible drilling fluid was investigated using a rotational viscometer with flushing acids, and the results are shown in Table 5; Figure 6.

The cleanup efficiency of the reversible drilling fluid increases as the $\mathrm{pH}$ decreases, and the viscometer cylinder surface returns to the waterwet state. The introduction of $\mathrm{H}^{+}$ions into the system leads to the protonation of RPEM, which facilitates reversion to the $\mathrm{O} / \mathrm{W}$ emulsion. Consequently, the residual $\mathrm{O} / \mathrm{W}$ emulsion on the viscometer is easily washed by the inherently water-based flushing fluids used in the cementing procedure. Even though a high $\mathrm{H}^{+}$concentration results in a high efficiency, it is suggested to use flushing fluids at a $\mathrm{pH}$ of 4-5 owing to the corrosion risk of metals exposed to acids. The cleanup efficiency of the reversible drilling fluid using flushing fluids at a $\mathrm{pH}$ of 4 is similar to that of using conventional surfactant flushing fluids.

\section{Drilled Cutting Disposal}

Oily drill cuttings that circulate on the surface cause severe environmental pollution. Therefore, it is necessary to investigate the possibility of reducing the oil content of the drill cuttings produced by reversible drilling fluids. The most common treatment technique used in the UK at present is indirect thermal desorption (Page et al., 2003). The oily drill cuttings produced by the reversible drilling fluid were washed with simple acids, and the resulting oil contents are shown in Table 6.

As shown in ; Figure 7, the oil content of the drill cuttings reduces from $35.5 \%$ to $1.3 \%$ when they are exposed to acids. The lower $\mathrm{pH}$ values help reverse oil-wet drill cuttings into water-wet drill cuttings.
Then, the drill cuttings return to their original orange color and easily disperse in water. In contrast, a high oil content remains for cuttings that are immersed in neutral liquids. Therefore, a reversible drilling fluid is beneficial for drilled cutting that are washed with acids, which provides a promising method to dispose oily drilled cuttings in cost-effective ways.

\section{CONCLUSION}

A type of $\mathrm{pH}$-responsive drilling fluid with a temperature resistance up to $150^{\circ} \mathrm{C}$ and a density of $1.5 \mathrm{~g} / \mathrm{cm}^{3}$ was prepared for deep or ultra-deep wells. Stable reversion from a W/O emulsion to an $\mathrm{O} / \mathrm{W}$ emulsion and vice versa was realized, which paved the way for practical reversion in the wellbore for different geological formation. The $\mathrm{W} / \mathrm{O}$ and $\mathrm{O} / \mathrm{W}$ emulsions exhibited small droplet sizes and uniform distributions. The W/O and $\mathrm{O} / \mathrm{W}$ emulsion-based drilling fluids showed excellent resistance to coalescence or sedimentation on the basis of light backscattering and SFs. There was no demulsification of the emulsions or barite sedimentation during emulsion reversion. The W/O and $\mathrm{O} / \mathrm{W}$ emulsion-based drilling fluids showed similar properties after hot rolling at $150^{\circ} \mathrm{C}$ for $16 \mathrm{~h}$. The $\mathrm{W} / \mathrm{O}$ emulsion exhibited excellent resistance to contamination by saline water and drill cuttings. The residual W/O emulsion-based drilling fluid was washed with acids at a high efficiency. The oil content of the drill cuttings generated by the reversible W/O emulsion-based drilling fluid was reduced using acids.

\section{DATA AVAILABILITY STATEMENT}

The original contributions presented in the study are included in the article/supplementary material, further inquiries can be directed to the corresponding author.

\section{AUTHOR CONTRIBUTIONS}

Conceptualization, LL. Funding acquisition, DL, JJ; review and editing, LL. DZ, JJ; Investigation, LL, XW, DL.

\section{FUNDING}

This study was supported by the Open Fund of the State Key Laboratory of Shale Oil and Gas Enrichment Mechanisms and Effective Development (grant no. 20-YYGZ-KF-GC-03). 


\section{REFERENCES}

Ali, S., Bowman, M., R Luyster, M., Patel, A., Svoboda, C., McCarty, R. A., et al. (2004). Reversible Drilling-Fluid Emulsions for Improved Well Performance. Oilfield Rev. 16 (3), 62-68.

Bageri, B. S., Adebayo, A. R., Barri, A., Al Jaberi, J., Patil, S., Hussaini, S. R., et al. (2019). Evaluation of Secondary Formation Damage Caused by the Interaction of Chelated Barite with Formation Rocks during Filter Cake Removal. J. Pet. Sci. Eng. 183, 106395. doi:10.1016/j.petrol.2019.106395

Bageri, B. S., Gomaa, I., Mahmoud, M., Patil, S., and Al-Nakhli, A. (2020). Complex Barite Filter Cake Removal Using Iin-Ssitu Generated Acids by Thermochemicals. Sci. Rep. 10, 15773. doi:10.1038/s41598-020-72858-y

Binks, B. P., Murakami, R., Armes, S. P., and Fujii, S. (2005). Temperature-induced Inversion of Nanoparticle-Stabilized Emulsions. Angew. Chem. Int. Ed. 44 (30), 4795-4798. doi:10.1002/anie.200501073

Binks, B. P., and Rodrigues, J. A. (2007). Double Inversion of Emulsions by Using Nanoparticles and a Di-chain Surfactant. Angew. Chem. Int. Ed. 46 (28), 5389-5392. doi:10.1002/anie.200700880

Boyou, N. V., Ismail, I., Wan Sulaiman, W. R., Sharifi Haddad, A., Husein, N., Hui, H. T., et al. (2019). Experimental Investigation of Hole Cleaning in Directional Drilling by Using Nano-Enhanced Water-Based Drilling Fluids. J. Pet. Sci. Eng. 176, 220-231. doi:10.1016/j.petrol.2019.01.063

Brugger, B., and Richtering, W. (2007). Magnetic, Thermosensitive Microgels as Stimuli-Responsive Emulsifiers Allowing for Remote Control of Separability and Stability of Oil in Water-Emulsions. Adv. Mater. 19 (19), 2973-2978. doi:10.1002/adma.200700487

Chen, Y., Bai, Y., Chen, S., Ju, J., Li, Y., Wang, T., et al. (2014). Stimuli-responsive Composite Particles as Solid-Stabilizers for Effective Oil Harvesting. ACS Appl. Mater. Inter. 6 (16), 13334-13338. doi:10.1021/am504124a

Cui, Z.-G., Cui, C.-F., Zhu, Y., and Binks, B. P. (2012). Multiple Phase Inversion of Emulsions Stabilized by In Situ Surface Activation of CaCO3 Nanoparticles via Adsorption of Fatty Acids. Langmuir 28 (1), 314-320. doi:10.1021/la204021v

Cui, Z. G., Shi, K. Z., Cui, Y. Z., and Binks, B. P. (2008). Double Phase Inversion of Emulsions Stabilized by a Mixture of $\mathrm{CaCO}_{3}$ Nanoparticles and Sodium Dodecyl Sulphate. Colloids Surf. A. 329 (1), 67-74. doi:10.1016/j.colsurfa. 2008.06.049

Destribats, M., Lapeyre, V., Sellier, E., Leal-Calderon, F., Ravaine, V., and Schmitt, V. (2012). Origin and Control of Adhesion between Emulsion Drops Stabilized by Thermally Sensitive Soft Colloidal Particles. Langmuir 28 (8), 3744-3755. doi:10.1021/la2043763

Dick, M. A., Svoboda, C., and Jones, M. (2003). “Reversible Invert Emulsion System Used to Significantly Increase Water Injection Rates in an Open Hole, StandAlone Screen Completion in West Africa," in SPE European Formation Damage Conference, The Hague, Netherlands, May 13, 2003 (Society of Petroleum Engineers). doi:10.2118/82278-ms

Dyab, A. K. F. (2012). Destabilisation of Pickering Emulsions Using pH. Colloids Surf. A: Physicochemical Eng. Aspects 402, 2-12. doi:10.1016/j.colsurfa.2012. 02.041

Elkatatny, S. (2018). Enhancing the Stability of Invert Emulsion Drilling Fluid for Drilling in High-Pressure High-Temperature Conditions. Energies 11 (9), 2393. doi:10.3390/en11092393

Elkatatny, S. (2019). Mitigation of Barite Sagging during the Drilling of HighPressure High-Temperature wells Using an Invert Emulsion Drilling Fluid. Powder Tech. 352, 325-330. doi:10.1016/j.powtec.2019.04.037

Fujii, S., Cai, Y., Weaver, J. V. M., and Armes, S. P. (2005). Syntheses of Shell CrossLinked Micelles Using Acidic ABC Triblock Copolymers and Their Application as pH-Responsive Particulate Emulsifiers. J. Am. Chem. Soc. 127 (20), 7304-7305. doi:10.1021/ja050049a

Ghosn, R., Mihelic, F., Hochepied, J.-F., and Dalmazzone, D. (2017). Silica Nanoparticles for the Stabilization of W/O Emulsions at HTHP Conditions for Unconventional Reserves Drilling Operations. Oil Gas Sci. Technol. - Rev. IFP Energies Nouvelles 72 (4), 21-34. doi:10.2516/ogst/2017020

Guo, S., and Zhang, Y. (2019). CO2/N2-switchable High Internal Phase Pickering Emulsion Stabilized by Silica Nanoparticles and Low-Cost Commercial N,Ndimethyl-N-dodecylamine. Colloids Surf. A: Physicochemical Eng. Aspects 562, 119-126. doi:10.1016/j.colsurfa.2018.11.012
Guo, X., Xu, P., Xu, M., Cai, J., Huang, T., and He, M. (2020). Formation protection Method of Oil-based Drilling Fluid for Deep Fractured Tight Gas Reservoir. Energy Sci. Eng. 8 (10), 3682-3701. doi:10.1002/ese3.775

Haase, M. F., Grigoriev, D., Moehwald, H., Tiersch, B., and Shchukin, D. G. (2010). Encapsulation of Amphoteric Substances in a pH-Sensitive Pickering Emulsion. J. Phys. Chem. C 114 (41), 17304-17310. doi:10.1021/jp104052s

Mengual, O., Meunier, G., Cayré, I., Puech, K., and Snabre, P. (1999). TURBISCAN MA 2000: Multiple Light Scattering Measurement for Concentrated Emulsion and Suspension Instability Analysis. Talanta 50 (2), 445-456. doi:10.1016/ s0039-9140(99)00129-0

Nooripoor, V., and Hashemi, A. (2020). Effect of a Modified Nano clay and Nano Graphene on Rheology, Stability of Water-In-Oil Emulsion, and Filtration Control Ability of Oil-Based Drilling Fluids: A Comparative Experimental Approach. Oil Gas Sci. Technol. - Rev. IFP Energies Nouvelles 75, 40-55. doi:10.2516/ogst/2020032

Oltedal, V. M., Werner, B., Lund, B., Saasen, A., and Ytrehus, J. D. (2015). "Rheological Properties of Oil Based Drilling Fluids and Base Oils," in ASME 2015 34th International Conference on Ocean, Offshore and Arctic Engineering, St. John's, Newfoundland, Canada, May 31-June 5, 2015 (Petroleum Technology).

Page, P. W., Greaves, C., Lawson, R., Hayes, S., and Boyle., F. (2003). “Options for the Recycling of Drill Cuttings," in Paper presented at the SPE/EPA/DOE Exploration and Production Environmental Conference, San Antonio, Texas, USA, March 10-12, 2003. doi:10.2118/80583-ms

Patel, A., and Ali, S. (2003). "New Opportunities for the Drilling Industry through Innovative Emulsifier Chemistry," in International Symposium on Oilfield Chemistry, Houston, Texas, February 5-7, 2003 (Society of Petroleum Engineers). doi:10.2118/80247-ms

Patel, A. D., Mcglothlin, R. E., Bleier, R. D., and Brinkley, H. N. (1999). Oil Based Synthetic Hydrocarbon Drilling Fluid. US 5189012 02/23/1999.

Patel, A. D. (1999). "Reversible Invert Emulsion Drilling Fluids: A Quantum Leap in Technology," in IADC/SPE Asia Pacific Drilling Technology, Jakarta, Indonesia, September 07-09, 1998 (Society of Petroleum Engineers), 55-65. doi:10.2118/59479-pa

Popov, S. G., Natsepnskaya, A. M., Okromelidze, G. V., Garshina, O. V., Khvotscin, P. A., Grebneva, F. N., et al. (2013). "The Innovative Approach to Use of Emulsion Drilling Fluid - Reversible Inverted Drilling Fluid," in SPE Arctic and Extreme Environments Technical Conference and Exhibition, Moscow, Russia, October 15-17, 2013 (Society of Petroleum Engineers), 14. doi:10.2118/168661-ms

Quesada, M., Muniesa, C., and Botella, P. (2013). Hybrid PLGA-Organosilica Nanoparticles with Redox-Sensitive Molecular gates. Chem. Mater. 25 (13), 2597-2602. doi:10.1021/cm400700g

Read, E. S., Fujii, S., Amalvy, J. I., Randall, D. P., and Armes, S. P. (2004). Effect of Varying the Oil Phase on the Behavior of pH-Responsive Latex-Based Emulsifiers: Demulsification versus Transitional Phase Inversion. Langmuir 20 (18), 7422-7429. doi:10.1021/la049431b

Ren, J., Wang, Y., Jin, J., Wang, K., Guo, B., and Wang, X. (2017). “The Reversible Emulsion Controlled by Inorganic Salt at High Temperature or Low Permeability Reservoir," in SPE/IATMI Asia Pacific Oil \& Gas Conference and Exhibition, Jakarta, Indonesia, October, 2003 (Society of Petroleum Engineers), 11. doi:10.2118/186418-ms

Sharma, V., Jepson, D., Andrade e Sousa, E., Dompetelo, M., Zghal, J., Bermudez, R., et al. (2020). "Large-Scale Drill Cuttings Thermal Treatment and Slop System Retrofitted to Drillships during Zero-Discharge Drilling Operations Offshore Angola," in IADC/SPE International Drilling Conference and Exhibition, Galveston, Texas, March, 2020.

Shi, Y., Xiong, D., Chen, Y., Wang, H., and Wang, J. (2019). CO2-responsive Pickering Emulsions Stabilized by Iin-Ssitu Generated Ionic Liquids and Silica Nanoparticles. J. Mol. Liquids 274, 239-245. doi:10.1016/j.molliq.2018.10.096

Shi, Y., Xiong, D., Li, Z., Wang, H., Pei, Y., Chen, Y., et al. (2018). Highly Efficient and Reversible Inversion of a Pickering Emulsion Triggered by CO2/N2 at Ambient Conditions. ACS Sustain. Chem. Eng. 6 (11), 15383-15390. doi:10. 1021/acssuschemeng.8b03808

Tang, J., Quinlan, P. J., and Tam, K. C. (2015). Stimuli-responsive Pickering Emulsions: Recent Advances and Potential Applications. Soft Matter 11 (18), 3512-3529. doi:10.1039/c5sm00247h

Xu, M., Jiang, J., Pei, X., Song, B., Cui, Z., and Binks, B. P. (2018). Novel Oil-InWater Emulsions Stabilised by Ionic Surfactant and Similarly Charged Nanoparticles at Very Low Concentrations. Angew. Chem. Int. Ed. 57 (26), 7738-7742. doi:10.1002/anie.201802266 
Zhang, Y., An, P., and Liu, X. (2015). Bell-shaped Sol-Gel-Sol Conversions in pHResponsive Worm-Based Nanostructured Fluid. Soft Matter 11 (11), 2080-2084. doi:10.1039/c4sm02845g

Zhang, Y., Chu, Z., Dreiss, C. A., Wang, Y., Fei, C., and Feng, Y. (2013). Smart Wormlike Micelles Switched by CO2 and Air. Soft Matter 9 (27), 6217-6221. doi:10.1039/c3sm50913c

Zhang, Y., Guo, S., Wu, W., Qin, Z., and Liu, X. (2016). CO2-triggered Pickering Emulsion Based on Silica Nanoparticles and Tertiary Amine with Long Hydrophobic Tails. Langmuir 32 (45), 11861-11867. doi:10.1021/acs. langmuir.6b03034

Conflict of Interest: Author DL is employed by the SINOPEC.

The remaining authors declare that the research was conducted in the absence of any commercial or financial relationships that could be construed as a potential conflict of interest.
The handling editor declared a shared affiliation with one of the authors LL at time of review.

Publisher's Note: All claims expressed in this article are solely those of the authors and do not necessarily represent those of their affiliated organizations, or those of the publisher, the editors and the reviewers. Any product that may be evaluated in this article, or claim that may be made by its manufacturer, is not guaranteed or endorsed by the publisher.

Copyright $\odot 2022 \mathrm{Li}$, Jin, Zhang, Li, Wang and Liu. This is an open-access article distributed under the terms of the Creative Commons Attribution License (CC BY). The use, distribution or reproduction in other forums is permitted, provided the original author(s) and the copyright owner(s) are credited and that the original publication in this journal is cited, in accordance with accepted academic practice. No use, distribution or reproduction is permitted which does not comply with these terms. 